\title{
Research on Basic Properties of Alkali-Surfactant-Polymer Flooding Produced Water and Influence of Oil-Displacing Agent on Settlement
}

\author{
Zhang $\mathrm{D}^{1 *}$, Chen $\mathrm{M}^{1}$, Ren $\mathrm{L}^{2}$, Chen $\mathrm{Z}^{3}$ and Meng $\mathrm{X}^{3}$ \\ ${ }^{1}$ College of Chemistry and Pharmaceutical Engineering, Jilin Institute Chemical Technology, \\ Jilin, China \\ ${ }^{2}$ College of Aeronautical Engineering, Jilin Institute Chemical Technology, Jilin, China \\ ${ }^{3}$ Daqing Oilfield Design Institute, Daqing, China
}

Research Article

Volume 4 Issue 6

Received Date: November 30, 2020

Published Date: December 14, 2020

DOI: $10.23880 /$ ppej-16000242

*Corresponding author: Dawei Zhang, College of Chemistry and Pharmaceutical Engineering, Jilin Institute Chemical Technology, Jilin 132022, China, Email: zhangdaweikkkk@163.com

\section{Abstract}

The basic properties of alkali-surfactant-polymer (ASP) flooding produced water and effect of oil displacing agent on the stability of flooding produced water were obtained, through measuring and analysing water quality, oil content-settling time relationship and oil displacing agent-oil droplet size relationship of Zhong-106, Zhong-312, Zhong-417, Nan 4-8 and Bei 2-7 flooding produced water from Daqing Oilfield. The addition of ternary oil displacement agent to ASP flooding produced water greatly increases the difficulty of oil-water separation, and higher the concentration, worse the separation effect after standing. The effects of alkali, surfactant, and polymer on oil-water stability in simulated ASP flooding produced water were studied respectively. The ASP flooding produced water after 48 hours of settling formed a trace amount of nano-oil droplets, also accompanied by the accumulation and separation of a part of the oil droplets.

Keywords: ASP Flooding; Alkali; Polymer; Surfactant; Oil-content

\section{Introduction}

As an important oil recovery technology, ASP (alkalisurfactant-polymer) flooding has the remarkable characteristics of high oil displacement efficiency [1-4]. However, ASP flooding produced water contains a large amount of residual crude oil, oil displacement agents and suspended solids, so it is a relatively complex and stable emulsification system [5-8]. The treatment and re-injection of ASP flooding produced water from oilfields have brought huge challenges. Domestic and foreign researchers have carried out a lot of work on the treatment of produced water from ASP flooding. Li, et al. prepared a new type of silicasupported polyether polysiloxane quaternary ammonium salt demulsifier, which can effectively remove fine oil droplets in oil-in-water emulsions [9]. Wu, et al. using the method of magnesium hydroxide formed in situ to quickly remove and recover emulsified oil from ASP produced water [10]. Wang and Zhang, et al. studied the rheological properties of ASP produced water and analyzed the effect of the concentration of oil displacement agent on the stability of produced water [11-12]. This paper analyzes the water quality monitoring data of ASP flooding produced water from Zhong-106, Zhong-312, Zhong-417, Nan 4-8 and Bei 2-7 in Daqing Oilfield sewage station, and preliminarily summarizes the basic properties of ASP flooding and the influence of ternary oil displacement agent on oil-water separation characteristics. By analyzing the $\mathrm{pH}$, particle size, viscosity, and surface tension of ASP flooding produced water from the ternary system, it provides a theoretical basis for the treatment and 


\section{Petroleum \& Petrochemical Engineering Journal}

reinjection of ASP flooding produced water.

\section{Experimental}

\section{General Remarks}

ASP flooding produced water samples were taken from strong alkali (Zhong-106 and Zhong-418) and weak alkali (Zhong-312, Nan 4-8 and Bei 2-7) water treatment stations of Daqing Oilfield. The main components of oil displacement agent were partially hydrolyzed polyacrylamide, $\mathrm{Na}_{2} \mathrm{CO}_{3}$ (weak alkali station) and $\mathrm{NaOH}$ (strong alkali station), alkylbenzene sulfonate (weak alkali station) and petroleum sulfonate (strong alkali station), and all of them were independently developed by Daqing Oilfield. The $\mathrm{pH}$ of the water samples were measured using PHSJ-4A acidity meter (shanghai), and it has been calibrated before measurement. The viscosity of the water samples were determined by using an RS100 rheometer (German, equipped with DG40 test probe). The surface tension and contact angle of the water samples were collected by using OCA25 surface tension meter (German). Oil content of water samples were determined by using a 7230 spectrophotometer (Shanghai). Suspended solids content of water samples were determined by using a JBKG-1A suspended solids tester. The particle size distribution of oil droplets and suspended particles in water samples was measured by using dynamic light scattering particle size analyzer Viscotek 802DLS (USA).

\section{Separation Characteristics and Parameter Determination of ASP Produced Water}

Take ASP flooding produced water from the Sanyuan Station of Daqing Oilfield by using a $500 \mathrm{~mL}$ glass settling column to settle for $1 \mathrm{~h}, 2 \mathrm{~h}, 4 \mathrm{~h}, 8 \mathrm{~h}, 12 \mathrm{~h}, 18 \mathrm{~h}, 24 \mathrm{~h}, 32 \mathrm{~h}$, $48 \mathrm{~h}$ respectively. When the corresponding settling time is reached, take the settling column of the corresponding time, first discharge $100 \mathrm{~mL}$ of bottom water, and then respectively take $150 \mathrm{~mL}$ to measure the oil content and suspended solids content. Before the settling test, take about $200 \mathrm{~mL}$ water samples to test polymer, surfactant, alkali and $\mathrm{Na}^{+}, \mathrm{K}^{+}, \mathrm{Ca}^{2+}$, $\mathrm{Mg}^{2+}, \mathrm{HCO}_{3}{ }^{-}, \mathrm{CO}_{3}{ }^{2-}, \mathrm{Cl}^{-}, \mathrm{SO}_{4}{ }^{2-}$ content respectively.

\section{Preparation of Simulated ASP Produced Water}

Prepare $200 \mathrm{~mL}$ of water sample with $1000 \mathrm{ppm}$ of polymer and surfactant in a jar. Oil sample (200 g) was added to a jar and placed in a water bath at $40^{\circ} \mathrm{C}$ for 24 hours. The oil and water samples in jar were emulsified with a homogenizer (Switzerland, KINEMATICA, PT 3000) at a speed of $20000 \mathrm{r} / \mathrm{min}$ for $5 \mathrm{~min}$ to prepare a mother liquid of oil droplets with an oil content of $50 \%$. Prepare a water sample containing a certain amount of alkali, surfactant and polymer in a jar, add $1.0 \mathrm{~g}$ of the prepared oil bead mother liquid to the water sample and shake it manually 50 times to obtain a simulation with initial oil content of $2000 \mathrm{ppm}$ ASP flooding produced water. The contents of various ions in the simulated ASP flooding produced water are shown in Table 1.

\begin{tabular}{|c|c|c|c|c|c|c|c|}
\hline Item & $\mathrm{Na}^{+}$ & $\mathrm{Cl}^{-}$ & $\mathrm{CO}_{3}{ }^{2}-$ & $\mathrm{HCO}_{3}-$ & $\mathrm{Ca}^{2}+$ & $\mathbf{M g}^{2}-$ & $\mathrm{SO}_{4}{ }^{2}$ \\
\hline Ion content/ppm & 2342 & 1031.5 & 636.8 & 2625 & 12.5 & 8.1 & 6.1 \\
\hline
\end{tabular}

Table 1: Simulate the content of various ions in ASP flooding produced water.

\section{Results and Discussion}

\section{Study on the Basic Parameters of Produced Water from ASP Flooding}

As early as 2013, ASP flooding produced water treatment station began to be designed by Daqing Oilfield, with an operating scale of more than $10,000 \mathrm{~m}^{3} / \mathrm{d}$. The current ASP flooding produced water treatment process was that the raw water first underwent two-stage settling, which could be completed by the sequential batch reactor, and then passed through two-stage filtration, including quartz sandmagnetite double-layer filtration and glauconite-magnetite double-layer filtration, and finally re-injected (Figure 1). The results of the analysis of the properties of ASP produced water before the settling of Zhong-106, Zhong-312, Zhong-417, Nan4-8 and Bei 2-7 test stations are shown in Table 2.

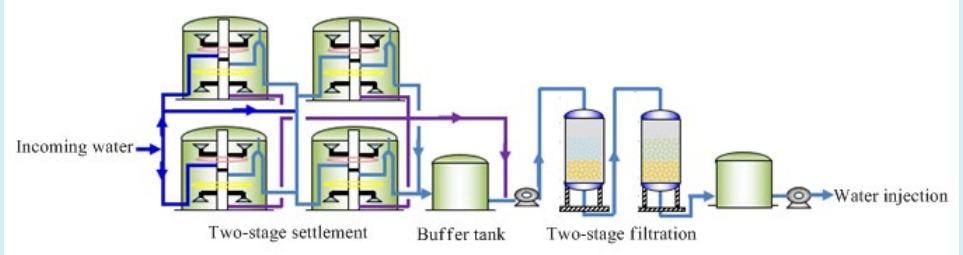

Figure 1: Schematic diagram of main process flow of Zhong-312 ASP flooding produced water treatment station. 


\section{Petroleum \& Petrochemical Engineering Journal}

\begin{tabular}{|c|c|c|c|c|c|}
\hline Item & Zhong-106 & Zhong-312 & Zhong-417 & Nan 4-8 & Bei 2-7 \\
\hline Temp. $/{ }^{\circ} \mathrm{C}$ & 39.3 & 40.7 & 38.8 & 40.2 & 40.5 \\
\hline$\rho($ Oil $) / \mathrm{ppm}$ & 585.9 & 854.4 & 489.1 & 455.3 & 386.8 \\
\hline$\rho$ (Polymer)/ppm & 779.4 & 866.3 & 821.8 & 718.9 & 669.3 \\
\hline$\rho($ Surfactant $) / \mathrm{ppm}$ & 89.2 & 66.7 & 80.4 & 36.6 & 29.3 \\
\hline$\rho($ Alkali $) / \mathrm{ppm}$ & 4434.5 & 4028 & 4828.1 & 3329.6 & 3110.2 \\
\hline$\rho($ Solids $) / \mathrm{ppm}$ & 44.1 & 55.8 & 73.2 & 50.8 & 61.7 \\
\hline$\rho\left(\mathrm{CO}_{3}{ }^{2}-\right) / \mathrm{ppm}$ & 3443.4 & 1629.1 & 3319.3 & 1421.6 & 426.6 \\
\hline$\rho\left(\mathrm{HCO}_{3}{ }^{-}\right) / \mathrm{ppm}$ & 2191.4 & 1728.7 & 2235 & 2396.1 & 3279.1 \\
\hline$\rho\left(\mathrm{Ca}^{2}+\right) / \mathrm{ppm}$ & 24.1 & 43.3 & 31.6 & 21.5 & 18.5 \\
\hline$\rho\left(\mathrm{Mg}^{2}+\right) / \mathrm{ppm}$ & 11.7 & 18.6 & 16.2 & 24.8 & 10.1 \\
\hline$\rho\left(\mathrm{K}^{+}+\mathrm{Na}^{+}\right) / \mathrm{ppm}$ & 4406.2 & 4750.6 & 3998.4 & 3611.4 & 3274.3 \\
\hline $\mathrm{pH}$ & 9.79 & 8.56 & 9.66 & 8.23 & 7.86 \\
\hline Conductivity $/ \mu \mathrm{S} \cdot \mathrm{cm}^{-1 \mathrm{~b}}$ & $5.87 \times 10^{4}$ & $4.82 \times 10^{3}$ & $7.24 \times 10^{4}$ & $1.16 \times 10^{4}$ & $1.45 \times 10^{4}$ \\
\hline Viscosity $/ \mathrm{mPa} \cdot \mathrm{s}$ & 2.08 & 1.64 & 1.35 & 1.16 & 0.92 \\
\hline Particle size/nm & 1683.7 & 4641 & 1004.2 & 1965.5 & 804.6 \\
\hline Surface Tension $/ \mathrm{mN} \cdot \mathrm{m}^{-1 \mathrm{c}}$ & 27.4 & 33.9 & 31.8 & 44.3 & 43.1 \\
\hline Contact angle $/{ }^{\circ} \mathrm{d}$ & 25.8 & 18.9 & 28.4 & 28.3 & 32.5 \\
\hline
\end{tabular}

Table 2: ASP flooding produced water basic parameter determination ${ }^{a}$.

${ }^{a}$ Each test item was the average of three repeated measurements.

${ }^{b}$ Conductivity of pure water $4.86 \mu \mathrm{S} / \mathrm{cm}$;

'Surface tension of pure water was $75.5 \mathrm{mN} / \mathrm{m}$;

${ }^{d}$ The contact angle of deionized water and glass was $36.1^{\circ}$.

From the experimental results in Table 2, it can be seen that ASP flooding produced water contains oil-displacing agents (alkali, surfactants and polymers), crude oil, suspended solids and a large amount of inorganic salts. Its water quality characteristics are mainly as follows: Because the oil-displacing agent contains a large amount of alkaline substances such as carbonate and bicarbonate, the $\mathrm{pH}$ of the produced water is distributed between 8-10, which is an alkaline system. ASP flooding produced water is a system with high oil content and suspended solids, in which the oil content is above $400 \mathrm{ppm}$. ASP flooding produced water contains up to $650-900 \mathrm{ppm}$ of polymer, which increases the viscosity of ASP flooding produced water. The mass concentration of surfactant exceeds $30 \mathrm{ppm}$, which is the most direct factor to reduce the surface tension of produced water that also has the dual effects of solubilizing crude oil and promoting emulsification, so that the oil content of ASP flooding produced water remains high.

\section{The Influence of ASP Flooding Produced Water Settling Time on Oil-Water Separation}

The stability of emulsion depends on the stability of oil droplets, which can generally be characterized by oil content
[13]. In this paper, the water samples of different ASP flooding produced water treatment stations were settled, and the oil content of the produced water with different settlement times was measured. The relationship between the settlement time and the oil content within $48 \mathrm{~h}$ is shown in Figure 2.

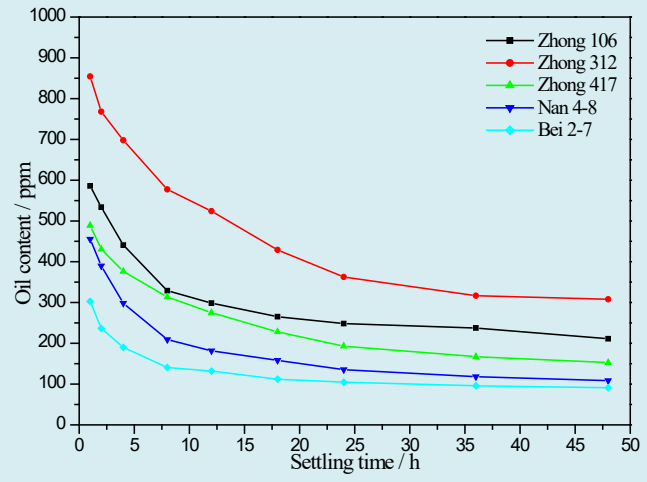

Figure 2: Effect of settling time on oil-water separation. 


\section{Petroleum \& Petrochemical Engineering Journal}

It can be seen from Figure 2 that with the extension of the settling time, the oil content of the produced water from each ASP flooding produced water treatment station shows a decreasing pattern. After the settling time is longer than 24 hours, the oil content of ASP flooding produced water decreases slowly, indicating that the emulsion formed by the produced water is relatively stable at this time, and the oil droplets are difficult to coalesce. In addition, the addition of oil-displacing agent is unfavorable to the settling of ASP flooding produced water and hinders the coalescence of oil droplets in flooding produced water.

\author{
Effect of Standing Time on the Settlement \\ Characteristics of Simulated ASP Produced \\ Water
}

In order to study the influence of oil displacement agent on oil content and settling time, simulated ASP flooding produced water with different oil displacement agent concentration was prepared. The relationship between the residual oil content of the simulated ASP flooding produced water and the settling time is shown in Table 3 and Figure 3.

\begin{tabular}{|c|c|c|c|c|}
\hline $\begin{array}{l}\text { Settling } \\
\text { time (h) }\end{array}$ & $\begin{array}{c}\text { Water drive } \\
\rho_{\mathrm{NaOH}}=\mathbf{0 p p m} \\
\rho_{\mathrm{HPAM}}=\mathbf{0 p p m} \\
\rho_{\text {Surfactant }}=\mathbf{0 p p m}\end{array}$ & $\begin{array}{c}\text { Low concentration } \\
\rho_{\text {NaOH }}=1000 p p m \\
\rho_{\text {HPAM }}=200 p p m \\
\rho_{\text {Surfactant }}=100 \text { ppm }\end{array}$ & $\begin{array}{c}\text { Medium concentration } \\
\rho_{\mathrm{NaOH}}=2000 \mathrm{ppm} \\
\rho_{\mathrm{HPAM}}=400 \mathrm{ppm} \\
\rho_{\text {Surfactant }}=200 \mathrm{ppm}\end{array}$ & $\begin{array}{c}\text { High concentration } \\
\rho_{\text {NaOH }}=3000 \mathrm{ppm} \\
\rho_{\mathrm{HPAM}}=600 \mathrm{ppm} \\
\rho_{\text {Surfactant }}=300 \mathrm{ppm}\end{array}$ \\
\hline 0 & 2000 & 2000 & 2000 & 2000 \\
\hline 1 & 883.6 & 1595.2 & 1789.5 & 1860.7 \\
\hline 2 & 628.9 & 1412.7 & 1587.2 & 1709.3 \\
\hline 4 & 414.7 & 1120.6 & 1252.9 & 1447.3 \\
\hline 8 & 247.1 & 758.5 & 956.7 & 1170.2 \\
\hline 12 & 116.6 & 527.3 & 692.3 & 908.6 \\
\hline 18 & 66.8 & 402 & 496.5 & 717.9 \\
\hline 24 & 41.4 & 349.1 & 404.4 & 540.7 \\
\hline 36 & 39.2 & 318.5 & 351.6 & 428.4 \\
\hline 48 & 33.9 & 299.2 & 322.1 & 390.7 \\
\hline
\end{tabular}

Table 3: Effect of settling time on oil-water separation ${ }^{a}$.

${ }^{a}$ All data are the average of three determinations

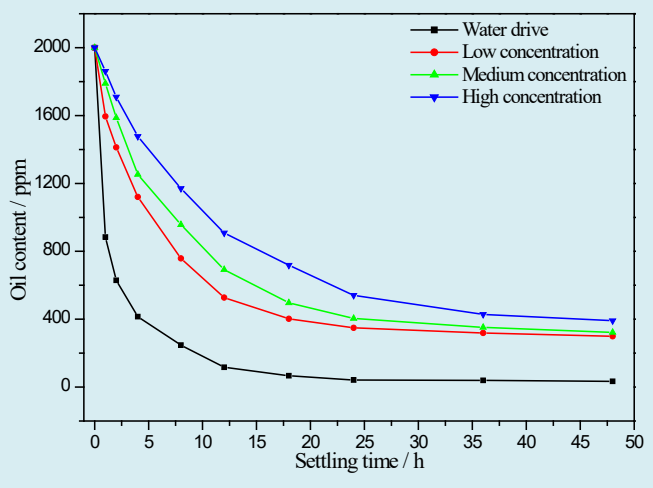

Figure 3: Effect of settling time on simulated oil-water separation.

It can be seen from Figure 3 that as the concentration of the ternary oil displacement agent increases, the rate at which the oil content in the simulated ASP flooding produced water decreases over time decreases. When the ternary oil displacement agent content is zero, the oil content drops from $2000 \mathrm{ppm}$ to $414.7 \mathrm{ppm}$ after standing for $4 \mathrm{~h}$. After that, the oil content decreases relatively slowly, and after 12 hours, the decrease rate is very slow. After the ternary oil displacement agent was added and left for $4 \mathrm{~h}$, the oil content of the low concentration, medium concentration and high concentration ASP flooding produced water were $1120.6 \mathrm{ppm}, 1252.9 \mathrm{ppm}$ and $1447.3 \mathrm{ppm}$, respectively. It shows that the addition of ternary oil displacement agent in ASP flooding produced water greatly increases the difficulty of oil-water separation, and the higher the concentration of ternary oil displacement agent, the worse the effect of standing separation.

\section{Influence of Ternary Oil Displacement Agent Content on Settlement Characteristics of Simulated ASP Produced Water}

The simulated ASP flooding produced water is taken out and added with a certain amount of alkali, surfactant 
and polymer. The variation range of the composition of the ternary oil-displacement agent in this experiment is: Alkali

\section{0-3000 ppm, surfactant 0-300 ppm, polymer 0-600 ppm.}
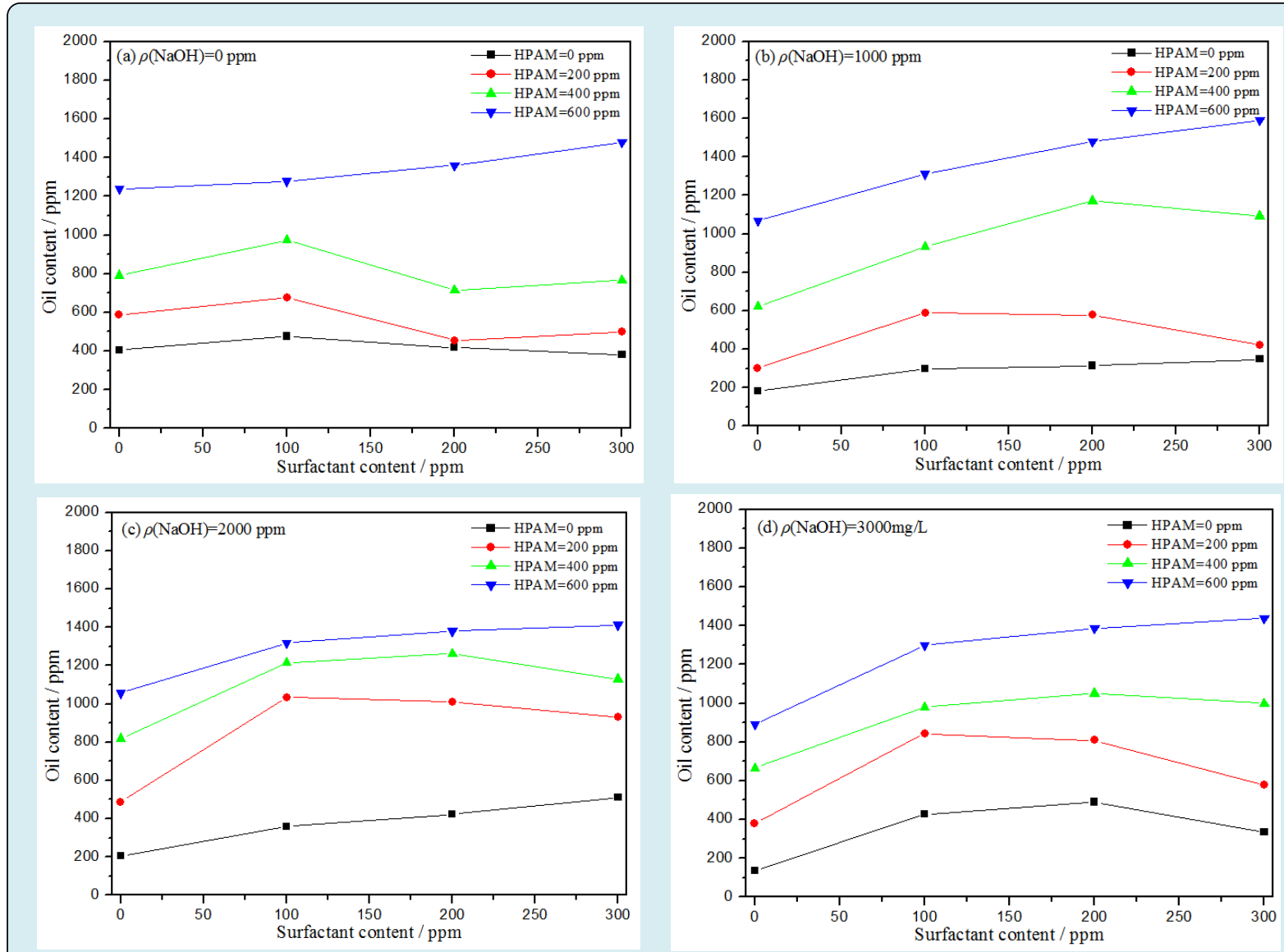

Figure 4: Influence of ternary oil displacement agent content on oil-water separation characteristics.

It can be seen from Figure 4 that when alkali exists alone and ternary coexist, oil-content first decreases with the increase of alkali concentration, then increases and then decreases. When alkali and high concentration polymer coexist, oil-content decreases with the increase of alkali concentration. In the actual oil recovery process, the alkali energy reacts with the organic acid in the crude oil to form a surfactant, which plays a positive role in stabilizing the oil droplets. Since the experiment uses simulated water samples, the contents of crude oil and organic acids in the water samples are low, so in the experimental results, effect of alkali on the oil-water separation of the simulated water samples is not significant.

Surfactant has a greater impact on oil-water separation that simulates ASP flooding produced water. When the surfactant exists alone, oil-content of simulated ASP flooding produced water increases first and then decreases with increase of surfactant concentration, and the cut-off point is $100 \mathrm{ppm}$. When surfactant and alkali coexist, oil-content of simulated ASP flooding produced water basically increases with the increase of surfactant concentration. When ternary oil displacement agents coexist, oil-content of simulated ASP flooding produced water first increases and then decreases with the increase of surfactant concentration. Surfactant reduces oil-water interfacial tension at low concentrations, making oil droplets more stable and difficult to aggregate and coalesce. With the increase of surfactant concentration, excessive micelles appear in the liquid phase, and the discharge osmotic pressure generated by the micelles between the droplets increases rate of droplet aggregation and coalescence. It can be seen that surfactant plays a doublesided effect on oil-water separation.

Polymer has the most significant effect on the simulated ASP flooding produced water oil-water separation. Regardless of whether polymer exists alone or coexists with alkali and surfactants, oil-content increases with increase of polymer concentration. 


\section{Petroleum \& Petrochemical Engineering Journal}

\section{Research on Particle Size Distribution and Change of ASP Produced Water}

The particle size distribution of oil droplets in produced water directly affects the difficulty of settling. The ASP flooding produced water after $0.22 \mu \mathrm{m}$ membrane filtration and settling for 2 and 48 hours was taken for particle size determination. The variation of ASP flooding produced water particle size distribution with time is shown in Figure 5.
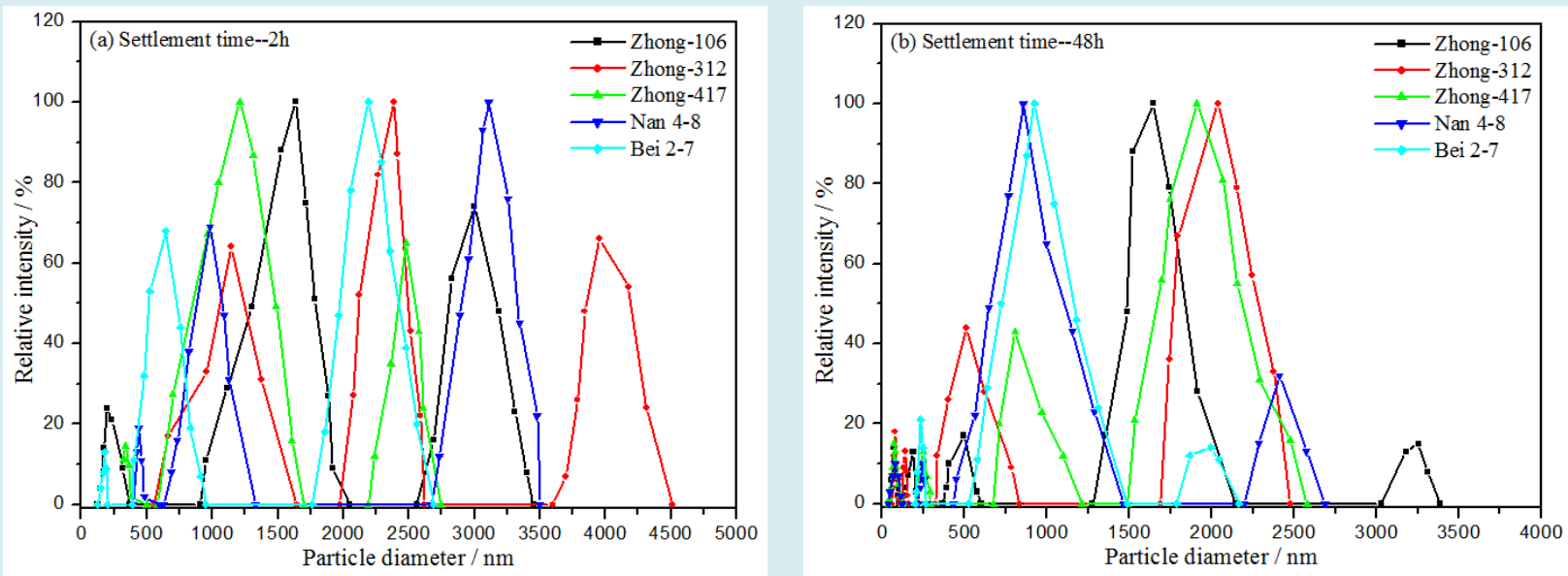

Figure 5: Particle size distribution of produced oil droplets in produced water after $40{ }^{\circ} \mathrm{C}$ gravity settling and $0.22 \mu \mathrm{m}$ membrane filtration.

It can be seen from Figure 5 that as the settling time becomes longer, the particle size of some oil droplets in the ASP produced water will become smaller, and the produced water of high ternary oil displacement agent is more obvious, and some oil droplets also accompany the aggregation and thus separate. After settling for 24 hours, a small amount of nano-oil droplets are formed in ASP flooding produced water, indicating that ASP flooding produced water is a strong stable system.

\section{Conclusions}

ASP produced water contains oil-displacing agent, crude oil, suspended solids and a large amount of inorganic salt at the same time, and the composition is complicated. Oildisplacing agents change the composition of ASP produced water, increase viscosity, reduce surface tension, and make oil-water separation difficult. Surfactant reduces oil-water interfacial tension at low concentrations, making oil droplets more stable and difficult to aggregate and coalesce. With the increase of surfactant concentration, excessive micelles appear in the liquid phase, and the discharge osmotic pressure generated by the micelles between the droplets increases rate of droplet aggregation and coalescence. Polymer has the most significant effect on the simulated ASP produced water oil-water separation. Regardless of whether polymer exists alone or coexists with alkali and surfactants, oil-content increases with the increase of polymer concentration. The particle size distribution of ASP produced water shows that after 24 hours of settling, a small amount of nano-oil droplets are formed in ASP produced water, indicating that ASP produced water is a very stable system. Therefore, exploring ways to effectively destroy the synergistic effect of oil-displacing agents is a key link in treatment of ASP produced water.

\section{Acknowledgments}

Financial support from the 'Science and Technology Research Project of Jilin Institute of Chemical Technology (2018035)' and 'Jilin Institute of Chemical Technology Ph.D. Starts Fund Project (2018007)' is gratefully acknowledged.

\section{References}

1. Huang B, Hu X, Fu C, Wang L (2020) Experimental evaluation of ASP flooding to improve oil recovery in heterogeneous reservoirs by layered injection approach. Energy Science \& Engineering 8(9): 3148-3164.

2. Samanta A, Bera A, Ojha K, Mandal A (2012) Comparative studies on enhanced oil recovery by alkali-surfactant and polymer flooding. Journal of Petroleum Exploration and Production Technology 2: 67-74.

3. Wang ZH, Yu TY, Lin XY, Wang XW, Su LS (2016) Chemicals loss and the effect on formation damage in reservoirs with ASP flooding enhanced oil recovery. Journal of 


\section{Petroleum \& Petrochemical Engineering Journal}

Natural Gas Science and Engineering 33: 1381-1389.

4. Zhapbasbayev UK, Kudaibergenov SE, Mankhanova AE, Sadykov RM (2018) Experimental study of alkalinesurfactant-polymer compositions for ASP-flooding of cores from highly viscous oil reservoirs. Thermophysics and Aeromechanics 25: 909-916.

5. Khan JA, Al-Kayiem HH, Aleem W, Saad AB (2019) Influence of alkali-surfactant-polymer flooding on the coalescence and sedimentation of oil/water emulsion in gravity separation. Journal of Petroleum Science and Engineering 173: 640-649.

6. Liu ZY, Li YQ, Luan HX, Gao WB, Guo Y, et al. (2019) Pore scale and macroscopic visual displacement of oil-inwater emulsions for enhanced oil recovery. Chemical Engineering Science 197: 404-414.

7. Li JR, Liu WD, Sun LH, Cong SA, Jia RX, et al. (2019) Effect of Emulsification on Surfactant Partitioning in Surfactant-Polymer Flooding. Journal of Surfactants and Detergents 22(6): 1387-1394.

8. Zhou YZ, Yin DY, Cao R, Zhang CL (2018) The mechanism for pore-throat scale emulsion displacing residual oil after water flooding. Journal of Petroleum Science and Engineering 163: 519-525.
9. Zhai MJ, Wu M, Wang CY, Li XB (2020) A novel silica-supported polyether polysiloxane quaternary ammonium demulsifier for highly efficient fine-sized oil droplet removal of oil-in-water emulsions. RSC Advances 10: 18918-18926.

10. Dong WJ, Sun DJ, Li YJ, Wu T (2018) Rapid removal and recovery of emulsified oil from ASP produced water using in situ formed magnesium hydroxide. Environmental Science: Water Research \& Technology 4: 539-548.

11. Wang B, Wu T, Li YJ, Sun DJ, Li X (2011) The effects of oil displacement agents on the stability of water produced from ASP (alkaline/surfactant/polymer) flooding. Colloids and Surfaces A: Physicochemical and Engineering Aspects 379(1-3): 121-126.

12. Zhang FS, Yang JO, He YW, Wang DW, Feng XF (2012) Study of the stability of the emulsion produced by alkaline surfactant polymer (ASP) flooding. Chemistry and Technology of Fuels and Oils 47: 434-439.

13. Li F, He WW, Sun DJ, Wu T, Li Y (2015) Effect of sodiummontmorillonite particles on the stability of oil droplets in produced water from alkali/ surfactant/polymer flooding. Journal of Cleaner Production 104: 468-474. 